\title{
The impact of sludge return liquors on South African wastewater treatment plants
}

\author{
Olivier Nsengiyumva', Yuva Coothen', David Ikumi' and Kirshen Naidoo² \\ 'Water Research Group, Department of Civil Engineering, University of Cape Town, Rondebosch, 7700, Cape Town, South Africa \\ ${ }^{2}$ Royal HaskoningDHV, Building No. 5 Country Club Estate, 21 Woodlands Drive, Woodmead 2191, PO Box 867, Gallo Manor, 2052, South Africa
}

There have been three considerable shifts, in the past 20 years, in the conventional design and modelling of wastewater treatment plants (WWTPs): (i) single unit process to plant-wide modelling, (ii) consideration of WWTPs as water and resource recovery facilities (WRRFs), and (iii) the need to simplify WWTP models to allow their intake by new stakeholders (i.e. plant operators, designers and decision-makers) who use these models for evaluation of WWTP optimisation strategies. The latter shift has prompted the debate about model complexity versus the required modelling purpose among modellers. In addition to the aforementioned shifts, there has been limited research on the impact of sludge recycling dewatering liquor on the overall plant performance, especially in the context of South African WWTPs. A simplified full-scale steady-state WWTP simulation tool was developed, based on principles of sound mass-balance stoichiometry and rate-limiting kinetics. This tool enables the user to analyse the impact of recycling the DWL on the plant performance through different scenarios. The strategic scenarios evaluated included the implementation of two side-stream treatment processes (STPs), namely BABE and struvite precipitation. The evaluation of various strategies was done using the benchmark simulation model (BSM) task group plant performance indices (i.e. effluent quality and operational cost indices, $\mathrm{EQI}$ and $\mathrm{OCl}$, respectively) incorporated into the simplified steady-state fullscale models. The integration of STP in the WWTP layout results in better EQI and OCI. The composition of the DWL affects the choice of the STP to be used, i.e., for DWL from an AD treating WAS that is not P-rich the recommended side-stream treatment operation would be the BABE process rather than struvite precipitation.

\section{INTRODUCTION}

Wastewater treatment plants (WWTPs) are designed, primarily, to remove pollutants from municipal or industrial wastewater, through a series of physical, chemical and biological processes, before releasing it into the receiving water bodies (Hreiz et al., 2015). The removal of these pollutants (including organics, and nutrients such as nitrogen and phosphorus), pre-1980, was done based on experience and empirical relationships (Ikumi, 2011). However, this resulted in inaccuracies and inadequacy, which prompted more research on how to optimise the design and operation of WWTPs. Dynamic simulation models were developed based on the principles of material mass balance to replicate processes happening in these plants. However, these models are complex models. They use varying flows and loads to evaluate the time-dependent response of the plant due to dynamic loading conditions (Ekama and Wentzel, 2008a). They require the knowledge of the sludge age, reactor volumes, interconnecting recycle flows and wastewater characteristics for design and operation. Hence, an iterative trial-and-error process is used to replicate WWTP process and operation. On the contrary, steady-state models are simple WWTP models developed based on the stoichiometry and rate-limiting kinetics of the system processes. They are often used to determine the system design and operation parameters (i.e., sludge age, reactor volume, recycle flows and wastewater characterisation) to meet a specified performance criterion such as effluent quality (Wentzel, et al., 2006; Ikumi, 2011). Thus, steady-state models are useful in complementing dynamic models by enabling the design and operation parameters to be determined before performing simulations and hence removing the need for a trial-and-error process.

Historically, WWTP models have been used by consulting engineers and researchers for design, process optimisation and to study interactions between various biological and chemical processes in WWTPs (Lizarralde et al., 2018). However, in the past 20 years, there have been three major recent shifts in the design and operation of wastewater treatment plants (WWTPs). Firstly, there has been a shift from single unit process to plant-wide modelling to study the interactions between various wastewater treatment processes. Secondly, WWTPs are to be considered as water and resource recovery facilities (WRRFs); this is motivated by the realisation of potential in recovering resources such as water, nutrients such as phosphorus, minerals and energy from the wastewater treatment processes (Mo and Zhang, 2013; Ekama, 2017). Thirdly, there has been a renewed interest in the utilisation of WRRF models by various stakeholders (i.e., plant operators, designers and decision-makers), including those with limited technical expertise in the WRRF processes - i.e., stakeholders use these tools for education on the relevant system processes and parameters and to assist them with decision-making during design and operation (Menniti et al., 2018). Though several plant-wide steady-state tools, such as the work of Wu and Ekama (2015) and Sötemann (2005), have been developed, the challenge with the currently developed simulation tools is that they are too complex and unrelatable to be used by stakeholders. Therefore, these tools required simplification to increase their uptake. Lizarralde et al. (2018) summarises the challenges that have to

\section{CORRESPONDENCE}

David lkumi

EMAIL

david.ikumi@uct.ac.za

\section{DATES}

Received: 7 November 2019

Accepted: 13 January 2021

\section{KEYWORDS}

WWTP full-scale modelling model simplification steady-state simulation plant performance indices BABE process struvite precipitation dewatering liquors

\section{COPYRIGHT}

() The Author(s) Published under a Creative Commons Attribution 4.0 International Licence (CC BY 4.0) 
be overcome in simplifying these tools: (i) the limited knowledge of the new stakeholders; (ii) the usefulness and trustworthiness of the information generated by these tools (i.e., the applicability of these tools); and (iii) simplifying the complex models without compromising their outputs. Menniti et al. (2018) recommend that, to overcome such challenges, the modeller should work closely with the involved stakeholders and that the accuracy of the model outcome should be made clear in the developmental stages of the model. Furthermore, stakeholders should be trained on how to use the models, where necessary. Simplified tools will enable decision-makers and plant designers to make better-informed decisions with regards to WRRF design and optimization. These are all relevant to the future of WRRF systems in developing countries, to allow for the shift from compliance-driven decision making to optimised design and operation of systems that are resource-recovery-driven.

In addition to the aforementioned developments in WRRF modelling, there has been limited research on the impact of sludge dewatering liquors (DWL) on overall plant performance, especially in the context of South Africa. Biological nutrient removal (BNR) activated sludge (AS) reactors produce secondary sludge, viz. waste activated sludge (WAS), that undergoes further stabilisation processes, in anaerobic or anoxic-aerobic digesters, before it can be disposed of. The digestion of WAS in the anaerobic digester usually produces a dewatering liquor that has a high concentration of nitrogen $(\mathrm{N})$ and phosphorus $(\mathrm{P})$. Recycling such a highly concentrated $\mathrm{N}$ and $\mathrm{P}$ liquor to the mainstream process overloads the plant with nutrients, with no added biodegradable organics to remove them (organics have a role to play in nutrient removal, through the provision of substrate for biomass growth and provision of electron donors in the process of denitrification). The result is often poor effluent quality and high operational costs (Vogts et al., 2015 and Ekama, 2017). Despite this, many WWTPs in South Africa generally recycle DWL to the mainstream treatment processes without further side-stream treatment. This publication provides the findings of a project that utilised wastewater treatment models as tools to evaluate the impact of recycling DWL to the BNR AS reactor and the benefits of integrating a side-stream treatment process (STP) in the WWTP system.

\section{MATERIAL AND METHODS}

The simplification of the complex steady-state WRRF models was accomplished through a collaborative process with different stakeholders. This involved: (i) consolidating WRRF single unit process models into an integrated plant-wide model (Ekama, 2009); (ii) developing a wastewater (WW) fractionator that reconciles influent WW measurements to reasonable WRRF model inputs; (iii) developing a user-friendly interface that guides the stakeholders towards the process of generating model predicted solutions; and (iv) verification of the model outputs (ensuring that the model was internally consistent and generating reasonable results).

\section{Simplified steady-state model}

There have been developments of complex steady-state (SS) single unit process models, such as the activated sludge (AS) process model (Marais and Ekama, 1976; Henze et al., 1987) and the anaerobic digestion (AD) model (Sötemann et al., 2005), with the aim of mimicking the $\mathrm{AS}$ and $\mathrm{AD}$ processes taking place in these units. The various previously developed single unit process models relevant to this project, namely, influent wastewater characterisation (Henze and Comeau, 2008), AS reactor (i.e. organism growth and decline (Ekama and Wentzel, 2008a), nitrification and denitrification models (Ekama and
Wentzel, 2008b), biological excess phosphorus removal models (Wentzel et al., 1990)) and anaerobic digestion of primary and secondary sludge, were linked together to form a plant-wide model, such that the outputs from upstream unit process become outputs for the downstream unit process. The full-scale SS model was formed based on the principles using the mass and chargebalanced bioprocess stoichiometry. Hence material (COD, $\mathrm{C}, \mathrm{H}, \mathrm{O}, \mathrm{N}$ and $\mathrm{P}$ ) mass balance calculations are an important tool to verify that the model is internally consistent (i.e. $100 \%$ mass balance is required for each material component). To ensure that elemental mass balance is achieved, it was required to comprehensively define the determined input components, through parameterizing the molar fractions of their elemental formula (i.e., $x, y, z$, $a$ and $b, \mathrm{C}_{x} \mathrm{H}_{y} \mathrm{O}_{z} \mathrm{~N}_{a} \mathrm{P}_{b}$ ). This enables tracking the various elements $(\mathrm{C}, \mathrm{H}, \mathrm{O}, \mathrm{N}$ and $\mathrm{P})$ throughout the virtual WWTP (Sötemann, 2005; Ekama, 2009; Ikumi et al., 2015; Ekama, 2017). All material mass balance for COD, C, H, O, $\mathrm{N}$ and $\mathrm{P}$ were checked for this model and found to balance at $100 \%$. The parametrisation of elemental molar fractions is also done because the influent sewage composition for biodegradable organics may vary, depending on the source of the pollutants that make up the influent (Gaszynski et al., 2019). The SS plant-wide model simplification consisted of 2 steps: (i) the development of an influent probabilistic fractionator that was linked to the integrated SS plant-wide model (i.e., the fractionator generated influent characteristics as input into the plant-wide model), and (ii) hiding complex calculations and generating a user-friendly interface (see sections below) in which the user is allowed to select relevant parameters and variables from the explicit SS model to suit their interests.

\section{Wastewater fractionator}

Influent wastewater (WW) fractionation is done primarily to reconcile influent measured data so that the different input components can be determined. Wastewater characterisation is a key to success in the modelling; poor model inputs would result in inaccurate model predictions. The fractionator was developed with the aim of enabling the user to generate the required model influent component values, based on previous measurements and knowledge from the research. The outputs from the fractionator (i.e., wastewater constituents) were used as inputs into the activated sludge models for the biological processes.

\section{User interface development}

The development of a suitable user-friendly interface was done with the intent of bridging the gap in knowledge between modellers and stakeholders. This interface was developed using Microsoft Excel Visual Basic (VBA) coding. Interface development was a collaborative process that involved the participation of several stakeholders with different knowledge levels, i.e., ranging from those with a background in mathematical modelling to those with no modelling background at all.

\section{Model implementation}

To generate confidence on the model-predicted outputs, 4 steps were used: (i) fractionator validation, which consists of analysing whether the predicted wastewater fractionator outputs fall within acceptable ranges, (ii) an analysis was carried out by running the steady-state fractionator with varying influent wastewater constituents, namely, chemical oxygen demand (COD), total Kjeldahl nitrogen (TKN), and total phosphorus (TP), to examine which of these measurements has the biggest impact on the results, (iii) calculation of material mass balances over unit processes, i.e., model verification for internal consistency, and (iv) observation against selected full-scale WWTP systems. 


\section{Performance indices}

Performance indices are used as a means of evaluating design/ control strategies implemented in WWTPs. The performance indices incorporated in the tool are the effluent quality index (EQI) and the operational cost index (OCI) adopted from the International Water Association (IWA) Benchmark Simulation Modelling (BSM) task group (Jeppsson et al., 2007). Both the EQI and OCI are dependent on the limited predictions of steadystate plant-wide modelling and therefore should only be used as an estimate. The EQI standardises the pollutants discharged by applying weighting factors to each pollutant based on their relative environmental impact. The result is the number of pollutants (in terms of kg) discharged per day. The EQI and OCI formulations provided by De Ketele et al. (2018), based on the previous work by the IWA BSM task group (Jeppsson et al., 2007), are shown in Eq. 1 and Eq. 2, respectively. Since the tool is based on a steadystate model, the actual calculations are done in this case without time steps.

$$
\begin{aligned}
\mathrm{EQI}= & \left(\beta_{\mathrm{TSS}} \cdot \mathrm{TSS}+\beta_{\mathrm{COD}} \cdot \mathrm{COD}+\beta_{\mathrm{FSA}} \cdot \mathrm{FSA}+\right. \\
& \left.\beta_{\mathrm{NO}} \cdot \mathrm{NO}+\beta_{\mathrm{OP}} \cdot \mathrm{OP}\right) \cdot Q_{e}
\end{aligned}
$$

The $\beta$ factors for each pollutant in the EQI calculation are shown in Table 1 . These factors are directly related to the effluent concentration limits (e.g. $\beta_{\mathrm{FSA}}=\frac{\mathrm{COD} \text { conc }}{\mathrm{FSA} \text { conc }}=\frac{30}{2}=15$ ). The $\beta$ factors give an indication of how harmful pollutants are relative to COD; the larger the $\beta$ factor, the more harmful the pollutant.

The OCI is a measure of the operational cost of implementing design/control strategies at WRRFs. It is formulated as shown in Eq. 2. For the purposes of this tool, the OCI is limited to energy costs, more specifically aeration energy and methane production.

$$
\begin{aligned}
\mathrm{OCI}= & \left(A E \cdot \varepsilon_{\text {aeration }} \cdot 24-\mathrm{MP} \cdot \mathrm{ED}_{\mathrm{CH} 4} \cdot \varepsilon_{\mathrm{CH} 4 \text { motor }}\right) . \\
& \text { Energy cost } / 100
\end{aligned}
$$

where: $\mathrm{AE}$ is aeration energy $(\mathrm{kWh} / \mathrm{d}), \mathrm{ED}_{\mathrm{CH} 4}$ is the energy density of methane (15.42), MP is methane produced ( $\mathrm{kgCH} 4 / \mathrm{d})$, $\varepsilon_{\mathrm{CH} 4 \text { motor }}$ is the motor efficiency for $\mathrm{CH}_{4}(40 \%), \varepsilon_{\text {aeration }}$ is blower efficiency for aeration (85\%), energy cost is in cents/kWh.

Table 1. Beta weighting factors (adapted from De Ketele et al., 2018)

\begin{tabular}{lcc}
\hline Pollutant & Concentration limit (mg/L) & Default $\beta$-factor \\
\hline COD & 30.00 & 1 \\
FSA & 2.00 & 15 \\
OP & 1.50 & 20 \\
NO & 2.50 & 12 \\
TSS & 30.00 & 1 \\
\hline
\end{tabular}

\section{Side-stream treatment}

The mitigation measures, for ensuring that there is a lowered negative impact on the full-scale plant performance due to dewatering liquors, were analysed using two different technologies, namely bio-augmentation batch enhanced (BABE) process and struvite precipitation. The BABE process was deemed to be the suitable solution for South African plants because it is a low-cost method for $\mathrm{N}$ removal, and a simple operation allowing for an improved nitrification process in the main plant due to the recycling of nitrifiers from the side-stream treatment. With the challenges in South Africa (and other developing countries) in terms of capital investment and maintenance requirements, it appears the BABE technology may have an advantage compared to other, more complex, options. For P removal, amongst the wide variety of options for side-stream treatment (including conventional coagulation, flocculation and sedimentation using metal-salts for phosphorus chemical precipitation, as well as more complex processes with chemical crystallization in up-flow fluidized bed reactors with dosages of calcium or magnesium in controlled $\mathrm{pH}$ conditions and allowing for a high-phosphate recovery in the form of struvite), struvite precipitation was considered for this study. Despite the present South African market value for struvite recovery and application not being as cost-effective, compared with the conventional chemical precipitation solutions, the potential environmental and economic benefits of the application of sub-products, such as struvite, in agriculture/fertilizers and animal food industries and as construction materials, was deemed important for promotion of the required resource recovery. The bio-augmentation batch enhanced (BABE) process is a new lowcost method for N-removal in wastewater treatment. It allows for the removal of ammonia and the improvement of nitrifiers that are returned to the reactor via the recycle. The process consists of combining the sludge dewatering liquor with a fraction of the return AS from the BNR reactor into a nitrifying batch reactor with a short retention time (Fig. 1). To include denitrification, an anoxic tank is added to the process.

During the BABE process the return activated sludge is mixed with the sludge dewatering liquor in a side-stream nitrification/ denitrification reactor. Because of the high concentration of ammonia and high temperature, the growth of nitrifiers is boosted (i.e. there is growth of enhanced nitrifiers). The sludge with the enhanced nitrifiers is then returned to the main reactor. To model this requires some changes to be made in the nitrification equations (Ekama and Wentzel, 2008b) applied in the main reactor. This is because the input for the main reactor is dependent on the output of the side-stream reactor; and the input for the side-stream reactor is dependent on the output of the main reactor. Hence, with the implementation of the side-stream $\mathrm{BABE}$ process, the introduction

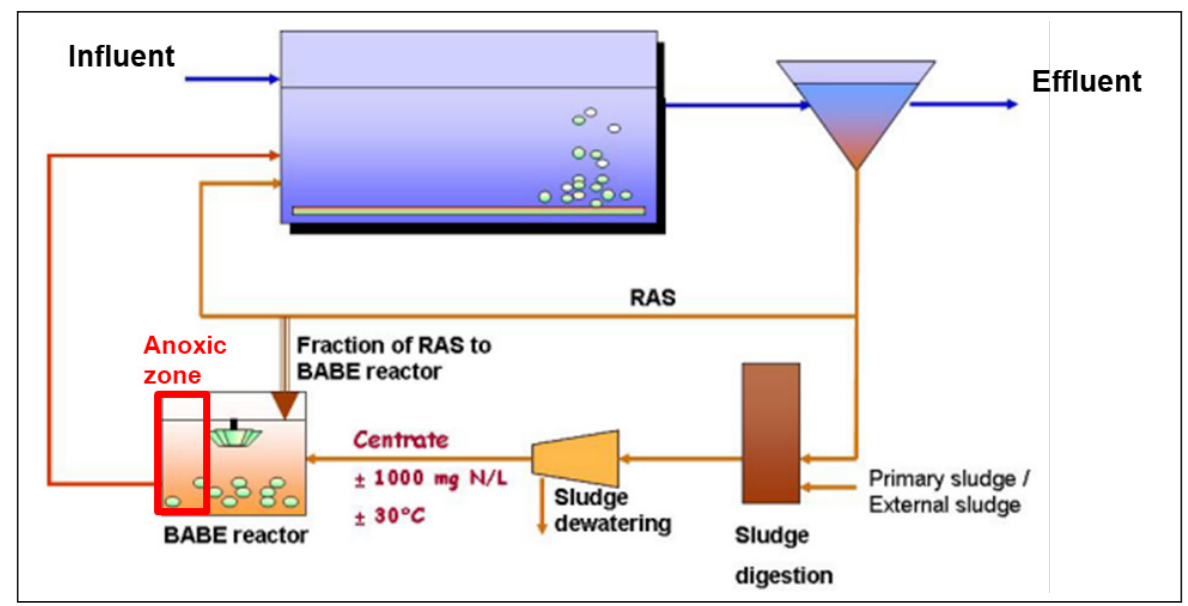

Figure 1. BABE process (adapted from Hommel et al., 2006) 
of a new term in the nitrification mass balance equation is added (Eq. 3). This term is known as the specific addition rate of nitrifiers $\left(k_{\text {add }}\right)$. It accounts for the nitrifiers grown in the side-stream reactor that are recycled back to the mainstream reactor. This $k_{\text {add }}$ is calculated as the ratio of the concentration of nitrifiers grown to the total concentration of nitrifiers (Salem et al., 2003).

$$
\frac{\mathrm{d} X_{\mathrm{BA}}}{\mathrm{d} t}=\text { growth }- \text { decay }- \text { wasting }+ \text { addition }
$$

Equation 3 shows the mass balance equation for the population of nitrifiers in the mainstream reactor, with the term 'addition' referring to the specific growth rate $k_{\text {add }}$. From the equation, the formulae for minimum SRT, effluent ammonia concentration and other predicted model variables can be derived for steady-state conditions.

Struvite $\left(\mathrm{MgNH}_{4} \mathrm{PO}_{4} \cdot 6 \mathrm{H}_{2} \mathrm{O}\right)$, is a phosphate mineral that is known to precipitate during the anaerobic digestion of sludge in the presence of magnesium ions (Ikumi and Ekama, 2019). Controlled struvite precipitation in the side stream, containing high concentrations of ammonium and phosphates, helps to reduce the nutrient load on the BNR reactor. Additionally, the struvite crystals precipitated can potentially be used as inorganic fertiliser (Nieminen, 2010).

$$
\begin{aligned}
& \mathrm{RMg}^{2+}+\mathrm{RNH}_{4}^{+}+6 \mathrm{H}_{2} \mathrm{O}+((1-f) \cdot \mathrm{R}) \mathrm{HPO}_{4}^{2-}+ \\
& ((1+f) \cdot \mathrm{R}) \mathrm{HCO}_{3}^{-}+(f \cdot R) \mathrm{H}_{2} \mathrm{PO}_{4}^{-} \rightarrow \\
& 6 \mathrm{MgNH}_{4} \mathrm{PO}_{4} \cdot 6 \mathrm{H}_{2} \mathrm{O}+((1+f) \cdot R) \mathrm{H}_{2} \mathrm{CO}_{3}
\end{aligned}
$$

Provided the ionic product of magnesium, ammonia and phosphate exceed the thermodynamic solubility of struvite, precipitation will occur (Loewenthal et al., 1994). By maintaining pH above 7 and dosing magnesium (if required), struvite precipitates, as shown in Eq. 4. With the number of moles of struvite $(R)$ precipitated calculated, the effluent ammonia and ortho-phosphates can be determined.

The recommendation pertaining to the best side-stream treatment option for each plant configuration was made with consideration to both the EQI and OCI using a weighted sum. For the purposes of the plant performance evaluation tool (PPET), the effluent quality index (EQI) was given a higher weight $(60 \%)$ than the operational cost index (OCI) (40\%) because the primary objective of WRRF is to achieve better effluent quality. It is recommended that, for future tool development, penalty costs used in certain areas be added to the OCI costs in order to motivate better practice, through it costs less to meet effluent standards than to save on operational costs while generating poor effluent.

\section{Case studies}

The developed steady-state (SS) simulation tool was used to conduct case studies on three different South African WWTPs (which were part of six pre-selected plants that represented typical South African plants). The aim of these case studies was to evaluate whether there would be an added benefit of incorporating sidestream treatment processes in WWTPs and to determine the most suitable process. For the sake of confidentiality, the names of the plants used have been changed to Plants A, B, and C.

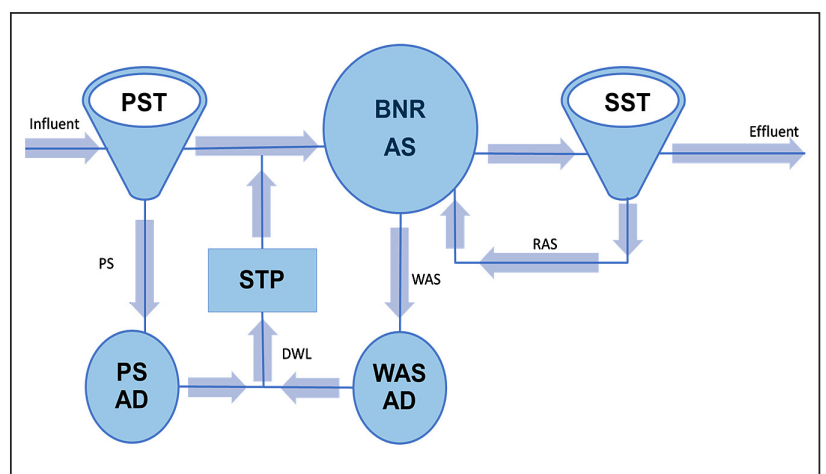

Figure 2. Simplified WWTP layout for Plants A, B and C: BNR AS biological nutrient removal activated sludge, DWL - dewatering liquor, PS - primary sludge, PS AD - primary sludge anaerobic digester, PST - primary settling tank, RAS - return activated sludge, SST - secondary settling tank, STP - side-stream treatment process, WAS AD - waste activated sludge anaerobic digester

The three different WWTPs that were used for the case studies are Plant A (University of Cape Town, UCT layout), Plant B (3-stage Phoredox layout) and Plant C (JHB layout) (Wentzel et al., 2008). Figure 2 is a simplified version of the WWTP layout showing the unit processes that were included in the developed tool because they are relevant to the research project. Table 2 summarises the general characteristics and unit processes/operations for the selected plants.

Below are the points considered when using the developed tool to virtually replicate the three plants $(\mathrm{A}, \mathrm{B}$ and $\mathrm{C})$ :

- Due to the limitation of the developed tool (i.e., it can only evaluate one module at a time), for Plants A and B which have more than one module, the tool was used to run only for the $40 \mathrm{ML} / \mathrm{d}$ module. More details about the plants used in the case studies are summarised below: Plant A consists of 4 modules each having a capacity of $40 \mathrm{ML} / \mathrm{d}$ besides Module 4 which has a capacity of $50 \mathrm{ML} / \mathrm{d}$. The primary sludge and waste activated sludge, produced in the four modules, is fed into one anaerobic digester of $12 \mathrm{ML} ; 50 \%$ of the produced DWL is recycled back to Modules $1-3$, while the remaining $50 \%$ goes to Module 4 .

- Plant B consists of 2 modules, the former having a capacity of $45 \mathrm{ML} / \mathrm{d}$ and the latter $40 \mathrm{ML} / \mathrm{d}$. The PS and WAS produced from each module are sent into separate anaerobic digesters. The resulting DWL is treated into 2 precipitation tanks where the lime slurry is dosed to increase the $\mathrm{pH}$ and precipitate orthophosphate. These tanks are also designed to strip ammonia. The treated DWL is recycled back at the beginning of Module 2 .

- Plant C consists of one module, a JHB BNR AS system with

\begin{tabular}{|c|c|c|c|c|c|c|c|}
\hline \multirow{2}{*}{$\begin{array}{l}\text { Unit processes } \\
\text { Plant }\end{array}$} & \multirow{2}{*}{$\begin{array}{c}\text { Sizes } \\
-\end{array}$} & \multicolumn{3}{|c|}{ Module 1} & \multicolumn{2}{|c|}{ Module $2 \& 3$} & \multirow{2}{*}{$\frac{\text { Module } 4}{\text { Plant A }}$} \\
\hline & & Plant A & Plant B & Plant C & Plant A & Plant B & \\
\hline PST & Diameter (m) & 25 & $4 \times 22$ & 25 & 25 & $3 \times 25$ & 34 \\
\hline BNR system & Volume $\left(\mathrm{m}^{3}\right)$ & 5940 & $2 \times 19575$ & 5940 & 15898 each & $2 \times 19575$ & 21688 \\
\hline SST & Diameter & 30 & $4 \times 32$ & 30 & 25 & $4 \times 35$ & 34 \\
\hline$A D$ unit & Volume $\left(\mathrm{m}^{3}\right)$ & - & $2 \times 6000$ & 424 & - & $2 \times 5380$ & - \\
\hline Module capacity & $\mathrm{ML} / \mathrm{d}$ & 40 & 45 & 9 & 40 & 40 & 50 \\
\hline
\end{tabular}
a capacity of $9 \mathrm{ML} / \mathrm{d}$. The WAS is anaerobically digested and the resulting DWL recycled back to the mainstream process.

Table 2. WWTP unit operations and processes for Plants A, B and C 


\section{Summary: application of the developed tool for case studies}

The SS simulation tool was developed in such a way that the input WWTP information of the selected system (i.e., influent wastewater characteristics, BNR AS configuration, operation and design parameters) directly resulted in the model being tailored to virtually replicate the relevant system processes. However, the developed tool is currently limited to running and analysing only one module at a time. The DWL recycled back from the thickening units was not considered in the side-stream treatment process because they contain an insignificant concentration of $\mathrm{N}$ and $\mathrm{P}$ compared to that in the DWL from the AD. All plants were assumed not to have any side-stream treatment process. Therefore, different scenarios were evaluated for operating the full-scale system with a percentage of DWL (0\% to 100\%) being treated before it is recycled back to the mainstream process.

\section{RESULTS AND DISCUSSION}

\section{Biological nutrient reactor}

The BABE process results in lowered minimum sludge age required for nitrification (Table 3). The reduction in the sludge age is associated with the fact that the BABE process recycles nitrifiers, produced in the $\mathrm{BABE}$ reactor, to the main treatment process. The addition of these nitrifiers in the AS reactor results in an improved nitrification process at a reduced sludge age (Salem et al., 2003), thus lower TKN content in the effluent (i.e., improved nitrification means less ammonium and TKN in the effluent, but total $\mathrm{N}$ cannot be reduced unless a specific denitrification section is present). In addition, the peak oxygen demand decreases with the integration of an STP unit. The recycling of the untreated DWL to AS results in increased oxygen demand to cater for nitrification requirements due to the high concentration of $\mathrm{N}$ load. The use of struvite precipitation as an STP results in lower nitrification oxygen demand in the parent AS system. This is due to some ammonia being used towards struvite $\left(\mathrm{MgNH}_{4} \mathrm{PO}_{4} \cdot 6 \mathrm{H}_{2} \mathrm{O}\right)$ in the precipitation process. However, ammonia is usually not the limiting component of the precipitation reaction - the precipitation of struvite usually gets limited by the quantity of magnesium present, with the acceptance of $\mathrm{pH}$ being maintained at a high value of above 7 . The BABE process produced the least oxygen demand because it recycles a lower $\mathrm{N}$ load compared to the struvite precipitation process.

\section{Anaerobic digestion}

The organically bound $\mathrm{N}$ and $\mathrm{P}$ nutrients are released in the aqueous phase during the anaerobic digestion (AD) of WAS. Consequently, the resulting DWL is rich in $\mathrm{N}$ and $\mathrm{P}$ nutrients; and if this liquor is recycled without undergoing further treatment, the plant would be overloaded with nutrients without enough biodegradable organics to facilitate the process of removing them. The BABE and struvite precipitation processes result in lowered $\mathrm{N}$ and P nutrients, respectively (Table 4). Following the AD of EBPR WAS that contains high $\mathrm{P}$ and metals, the struvite precipitation process, rather than $\mathrm{BABE}$, would be preferred because the $\mathrm{BABE}$ process would not be able to remove the excess $P$ that would end up being recycled back to the AS system and may eventually result in poor effluent quality (high $\mathrm{P}$ ). Otherwise, the option of recycling the $\mathrm{P}$ back to the AS system (i.e., after BABE process) may require a dosage of acetate in the anaerobic zone of the AS system to remove the excess $\mathrm{P}$ that came with the DWL. However, this is a significant operational cost and may result in increased sludge production (from the growth of PAO biomass), which may, in turn, pose a threat to the capacity of the system (i.e., the design volume and secondary settling tank surface allowed to cater for a specified maximum total solid concentration). If struvite precipitation is used as the STP, then the maintenance of high $\mathrm{pH}$ and ensuring the presence of usually limiting components such as magnesium would be necessary for maximum $P$ recovery as struvite.

\section{Effluent quality}

The incorporation of an STP in the WW treatment route improves the effluent quality. Table 5 compares the effluent concentration for different WW constituents for Plants A, B and C with the effluent quality special limit standards adapted from those enforced by the South African Department of Water and Sanitation (National Water Act, No. 36 of 1998, as amended, 2013; RSA, 1998).

Table 3. Biological reactor results for Plant $A$ for the option of recycling all (i.e., 100\%) of the AD DWL

\begin{tabular}{|c|c|c|c|c|c|c|c|c|c|}
\hline \multirow[t]{2}{*}{ Parameter } & \multicolumn{3}{|c|}{ Plant A } & \multicolumn{3}{|c|}{ Plant B } & \multicolumn{3}{|c|}{ Plant C } \\
\hline & No STP & BABE & Struvite & No STP & BABE & Struvite & No STP & BABE & Struvite \\
\hline Minimum sludge age for nitrification (d) & 8.35 & 8.24 & 8.35 & 8.35 & 8.26 & 8.35 & 4.45 & 4.40 & 4.45 \\
\hline Carbonaceous oxygen demand (kgO/d) & 7459 & 7459 & 7459 & 9794 & 6102 & 9773 & 873 & 866 & 866 \\
\hline Nitrification oxygen demand (kgO/d) & 5361 & 4832 & 4812 & 4347 & 4126 & 4162 & 675 & 661 & 671 \\
\hline Peak oxygen demand (kgO/d) & 9812 & 9561 & 9552 & 11730 & 7958 & 11641 & 1189 & 1176 & 1181 \\
\hline
\end{tabular}

Table 4. Dewatering liquor composition (mg/L) of Plants $A, B$ and $C$ for the option of treating $100 \%$ of the AD DWL

\begin{tabular}{|c|c|c|c|c|c|c|c|c|c|}
\hline \multirow[t]{2}{*}{ Parameter } & \multicolumn{3}{|c|}{ Plant A } & \multicolumn{3}{|c|}{ Plant B } & \multicolumn{3}{|c|}{ Plant C } \\
\hline & $A D$ & BABE & Struvite & $A D$ & BABE & Struvite & $A D$ & BABE & Struvite \\
\hline COD & 70.00 & 70.00 & 70.00 & 52.00 & 52.00 & 52.00 & 32.76 & 32.76 & 32.76 \\
\hline FSA & 255 & 9.01 & 175 & 287 & 9.01 & 155 & 231 & 9.01 & 180 \\
\hline OrthoP & 162 & 507 & 53.01 & 460 & 349 & 150 & 0.00 & 0.00 & 0.00 \\
\hline
\end{tabular}

Table 5. Effluent quality ( $\mathrm{mg} / \mathrm{L}$ ) for Plants A, B and C (shaded values indicate that the DWS special limits standards have been exceeded)

\begin{tabular}{|c|c|c|c|c|c|c|c|c|c|c|}
\hline \multirow[t]{2}{*}{ Parameter } & \multirow[t]{2}{*}{ Effluent quality } & \multicolumn{3}{|c|}{ Plant A } & \multicolumn{3}{|c|}{ Plant B } & \multicolumn{3}{|c|}{ Plant C } \\
\hline & & No STP & BABE & Struvite & No STP & BABE & Struvite & No STP & BABE & Struvite \\
\hline COD & 30.00 & 70.00 & 70.00 & 70.00 & 52.00 & 52.00 & 52.00 & 32.76 & 32.76 & 32.76 \\
\hline Ammonia & 2.00 & 2.20 & 2.20 & 2.20 & 2.20 & 2.10 & 2.20 & 0.60 & 0.60 & 0.60 \\
\hline NO3 & 1.50 & 5.19 & 4.76 & 4.75 & 6.14 & 6.72 & 6.79 & 5.49 & 6.08 & 6.17 \\
\hline PO4 & 2.50 & 0.89 & 1.16 & 0.91 & 12.17 & 8.91 & 6.74 & 1.13 & 1.43 & 1.43 \\
\hline
\end{tabular}


The values highlighted are those where the special limit standards are exceeded. The marginal increase in the effluent $\mathrm{PO}_{4}$ (Plants $\mathrm{A}$ and $\mathrm{C}$ ) and $\mathrm{NO}_{3}$ concentrations (Plants $\mathrm{B}$ and $\mathrm{C}$ ) is due to dilution effects (i.e., the hydraulic retention time is decreased with increased flows to the influent with the recycling of dewatering liquors back to the AS system). Figures 3 to 5 further elaborate on the benefits of integrating STP in the WW treatment layout, with respect to effluent quality and operational cost.

\section{Plant performance}

Both the EQI and OCI decrease with an increase in the percentage of DWL treated in the STP (see Figs 3-5). The EQI varies with respect to STP use for the plants under consideration, i.e., for Plants A and B, the struvite precipitation achieves lower EQI for the percentage of $40 \%$ and above of treated DWL; however, for Plant $\mathrm{C}$, the BABE process achieves a lower EQI. The BABE process achieves lower OCI than the struvite precipitation process, because the former process uses the same quantity of oxygen in the breakdown of ammonia (conversion to nitrates) from the dewatering liquor, and further oxygen for the endogenous process for biomass added to the BABE process from the AS system. On the other hand, struvite precipitation uses ammonia directly (from aqueous $\mathrm{NH}_{4}$ to solid-phase struvite, $\mathrm{MgNH}_{4} \mathrm{PO}_{4} \cdot 6 \mathrm{H}_{2} \mathrm{O}$ ) without imposing a significant increase in aeration energy requirements.

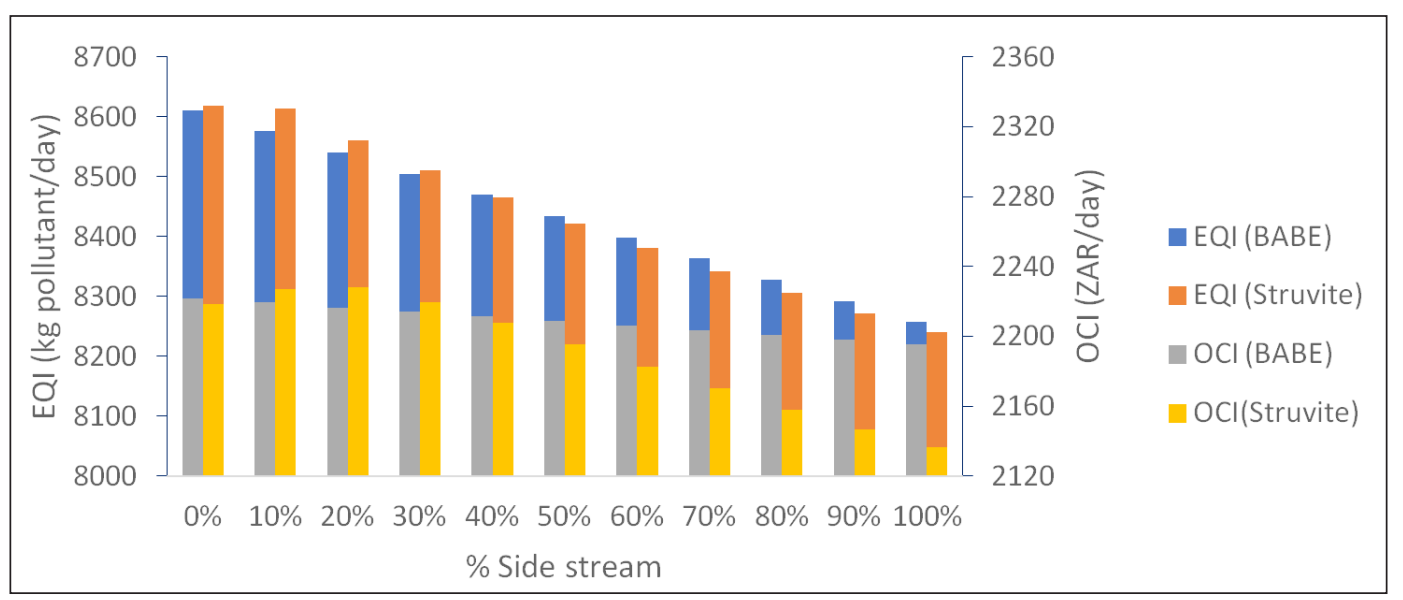

Figure 3. $\mathrm{EQI}$ and $\mathrm{OCl}$ variation with the percentage of DWL treated for Plant $\mathrm{A}$

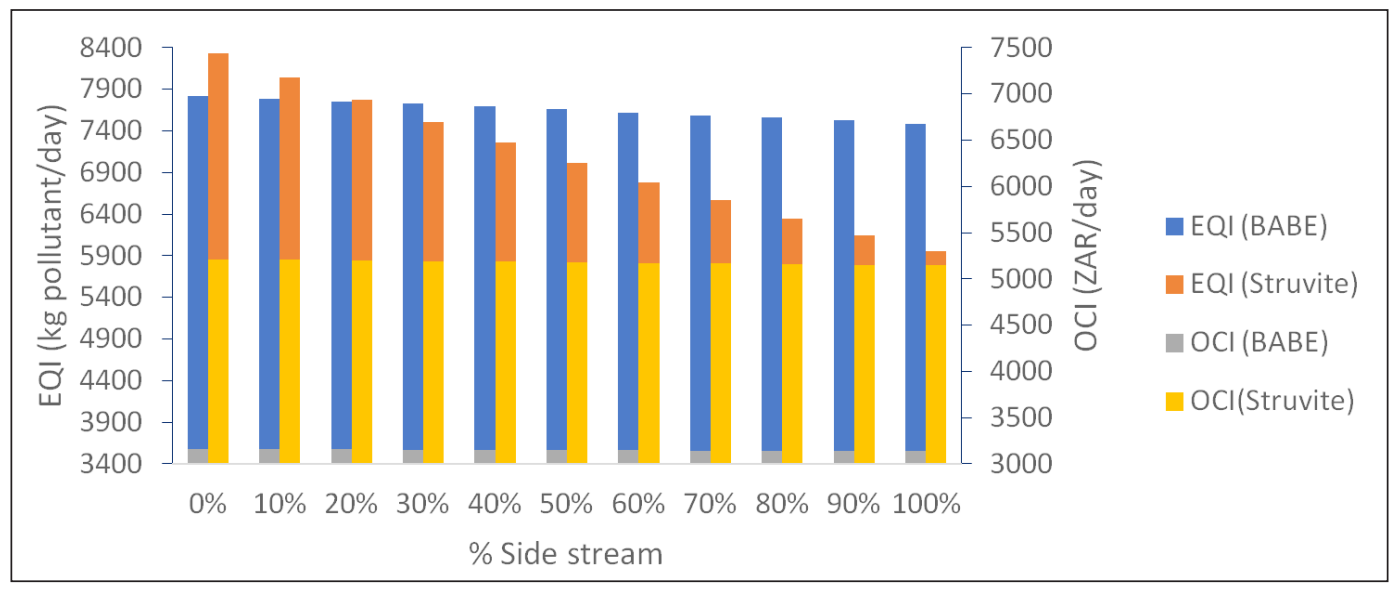

Figure 4. $\mathrm{EQI}$ and $\mathrm{OCl}$ variation with the percentage of DWL treated for Plant $\mathrm{B}$

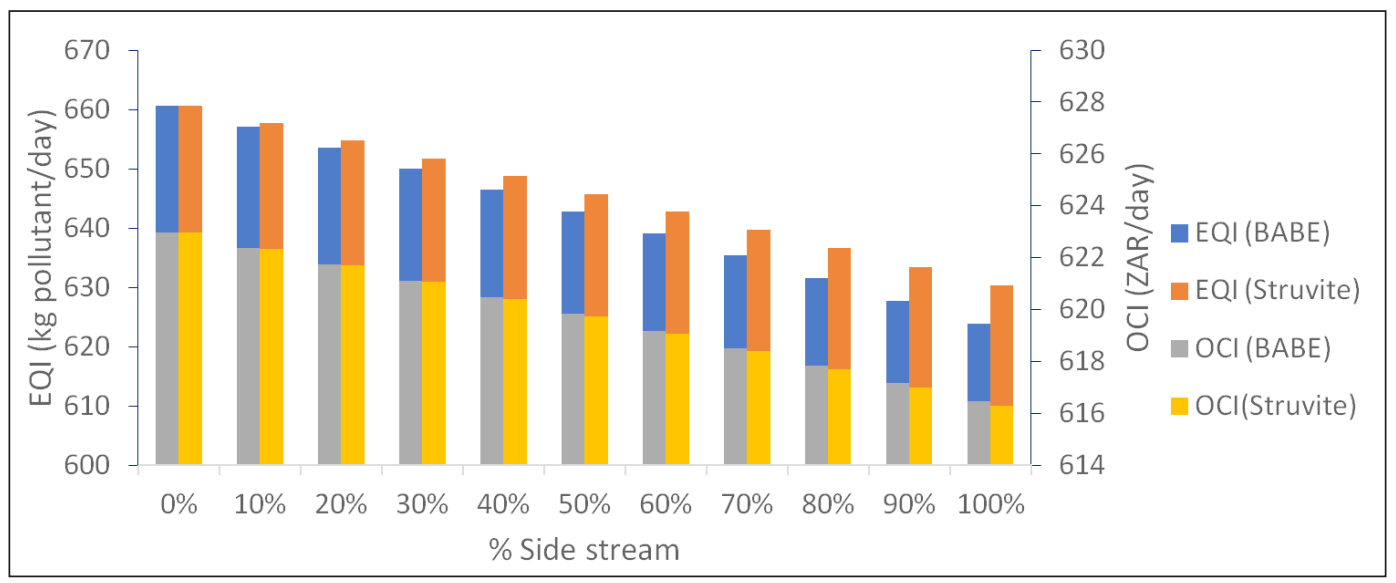

Figure 5. EQI and OCl variation with the percentage of DWL treated for Plant $C$ 


\section{CONCLUSIONS}

In conclusion, it is possible to simplify complex plant-wide steadystate tools into simple evaluation tools; however, the challenge of the accuracy of the tool outputs remains. The plant performance evaluation tool that was developed enables stakeholders to evaluate the impact of different design and operation conditions on the overall plant performance. According to the results from the SS plant-wide tool, there are added benefits of using a side-stream treatment process (i.e. BABE process and struvite precipitation) to mitigate the detrimental impacts of recycled DWL when the capacity of the plant has been exceeded. Both side-stream processes achieve different results based on the composition of the DWL that is being treated, i.e., for DWL from an AD treating WAS that is not P-rich (i.e., with low EBPR), the recommended sidestream treatment operation would be the $\mathrm{BABE}$ process rather than struvite precipitation. Due to the different treatment systems (i.e., with variations in influent loads, system configurations and priority end-products required - energy, water, phosphorus, etc.), further investigations are required on strategies for implementation of the various side-stream treatment processes. Furthermore, it is also recommended that for future development the penalty cost associated with exceeding the effluent quality limits be incorporated in the operational costs index, to discourage poor effluent discharge at lower costs.

\section{ACKNOWLEDGEMENTS}

This research was supported by the Water Research Commission, the University of Cape Town and Royal HaskoningDHV.

\section{REFERENCES}

DE KETELE J, DAVISTER D and IKUMI D (2018) Applying performance indices in plantwide modelling for a comparative study of wastewater treatment plant operational strategies. Water SA. 44 (4) 539-550. https://doi.org/10.4314/wsa.v44i4.03

EKAMA G (2009) Using bioprocess stoichiometry to build a plant-wide mass balance based steady-state WWTP model. Water Res. 43 (8) 2101-2120. https://doi.org/10.1016/j.watres.2009.01.036

EKAMA G (2017) Optimizing water and resource recovery facilities (WRRF) for energy generation without compromising effluent quality. IWA 2017 Conference.

EKAMA G and WENTZEL M (2008a) Chapter 4: Organic removal. In: Henze M, Van Loosdrecht MCM, Ekama G and Brdjanovic D (eds) Biological Wastewater Treatment: Principles, Modelling and Design. IWA Publishing, London. 53-86.

EKAMA G and WENTZEL M (2008b) Chapter 5: Nitrogen removal. In: Henze M, Van Loosdrecht MCM, Ekama G and Brdjanovic D (eds) Biological Wastewater Treatment: Principles, Modelling and Design. IWA Publishing, London. 87-138.

GASZYNSKI CE, IKUMI DS and EKAMA GA (2019) Utilization of augmented batch tests to determine sludge composition. Proc. IWA Watermatex2019, 1-4 Sept 2019, Copenhagen.

HENZE M, GRADY CPL (Jr), GUJER W, MARAIS GVR and MATSUO T (1987) Activated Sludge Model No. 1(ASM1). IWAPRC Scientific and Technical Report No. 1. IWAPRC, London.

HENZE $M$ and COMEAU Y (2008) Chapter 3: Wastewater Characterization. In: Henze M, Van Loosdrecht MCM, Ekama GA and Brdjanovic D (eds) Biological Wastewater Treatment: Principles, Modelling and Design. IWA Publishing, London. 33-52.

HOMMEL B, ZANDT E, BERENDS D and CLAESSEN V (2006) First application of the babe process at 'S-Hertogenbosch WWTP. Proc. Water Environment Federation. 2006 (7) 5227-5236. https://doi. org/10.2175/193864706783763165
HREIZ R, LATIFI M and ROCHE N (2015) Optimal design and operation of activated sludge processes: state-of-the-art. Chem. Eng. J. 281 900-920. https://doi.org/10.1016/j.cej.2015.06.125

IKUMI D (2011) The development of a three-phase plant-wide mathematical model for sewage treatment. $\mathrm{PhD}$ thesis, University of Cape Town.

IKUMI D and EKAMA G (2019) Plantwide modelling - anaerobic digestion of waste sludge from parent nutrient $(\mathrm{N}$ and $\mathrm{P})$ removal systems. Water SA. 45 (3) 305-316. https://doi.org/10.17159/wsa/ 2019.v45.i3.6698

JEPPSSON U, PONS MN, NOPENS I, ALEX J, COPP JB, ROSEN C, STEYER JP and VANROLLEGHEM PA (2007) Benchmark simulation model no 2: General protocol and exploratory case studies. Water Sci. Technol. 56 (8) 67-78. https://doi.org/10.2166/ wst.2007.604

LIZARRALDE I, FERNÁNDEZ-ARÉVALO T, AYESA E, FLORESALSINA $\mathrm{X}$, JEPPSSON U, SOLON $\mathrm{K}$, VANROLLEGHEM $\mathrm{P}$, VANEECKHAUTE C, IKUMI D, KAZADI MBAMBA C, BATSTONE D and GRAU P (2018) From WWTP to WRRF: A new modelling framework. In: $6^{\text {th }}$ IWA/WEF Water Resource Recovery Modelling Seminar, 10-14 March 2018, Québec.

LOEWENTHAL R, KORNMÜLLER $U$ and VAN HEERDEN E (1994) Modelling struvite precipitation in anaerobic treatment systems. Water Sci. Technol. 30 (12) 107-116. https://doi.org/10.2166/ wst.1994.0592

MARAIS GVR and EKAMA GA (1976) The activated sludge process: Part I - Steady state behaviour. Water SA. 2 (4) 163-200.

MENNITI A, ANDRES H, BELIA E, CARSON K, PASSARO S, PENA-TIJERINA A, REEVES $M$, SCHRAA O, SEIB $M$ and SNOWLING S (2018) Process modelling at resource recovery utilities: lessons learned and missing tools. In: $6^{\text {th }} I W A / W E F$ Water Resource Recovery Modelling Seminar, 10-14 March 2018, Québec.

MO W and ZHANG Q (2013) Energy - nutrients - water nexus: Integrated resource recovery in municipal wastewater treatment plants. J. Environ. Manage. 127 255-267. https://doi.org/10.1016/j. jenvman.2013.05.007

NIEMINEN J (2010) Phosphorus recovery and recycling from municipal wastewater sludge. MSc. Thesis, Aalto University.

RSA (Republic of South Africa) (2013) National Water Act. Act 36 of 1998, updated 2013. Government Gazette. 6 September 2013. Government notice no. 665. Government Printer, Cape Town.

SALEM S, BERENDS D, HEIJNEN J and VAN LOOSDRECHT M (2003) Bio-augmentation by nitrification with return sludge. Water Res. 37 (8) 1794-1804. https://doi.org/10.1016/S0043-1354(02)00550-X

SÖTEMANN S, RISTOW N, WENTZEL M and EKAMA G (2005) A steady state model for anaerobic digestion of sewage sludges. Water SA. 31 (4) 511-516. https://doi.org/10.4314/wsa.v31i4.5143

VOGTS M (2015) The removal of nitrogen and phosphorus in anoxicaerobic digestion of waste activated sludge from biological nutrient removal systems. Masters thesis, University of Cape Town.

WENTZEL MC, DOLD PL, EKAMA GA and MARAIS GVR (1990) Biological excess phosphorus removal - steady state process design. Water SA. 16 (1) 29-48.

WENTZEL M, EKAMA G and SÖTEMANN S (2006) Mass balancebased plant-wide wastewater treatment plant models - Part 1: Biodegradability of wastewater organics under anaerobic conditions. Water SA. 32 (3) 269-275. https://doi.org/10.4314/wsa.v32i3.5261

WENTZEL M, COMEAU Y, EKAMA G, VAN LOOSDRECHT M and BRDJANOVIC D (2008) Chapter 7: Enhanced biological phosphorus removal. In: Henze M, Van Loosdrecht MCM, Ekama G and Brdjanovic D (eds) Biological Wastewater Treatment: Principles, Modelling and Design. IWA Publishing, London. 155-220.

WU W and EKAMA G (2015) Development of a plant-wide steadystate wastewater treatment plant design and analysis program. MSc thesis, University of Cape Town. 